\title{
$\mathrm{T}$ \\ - опическая терапия инфицированных стероидчувствительных дерматозов
}

\author{
И.Е. Торшина
}

ГБОУ ВПО «Смоленский государственный медицинский университет» Минздрава России 214019, г. Смоленск, ул. Крупской, д. 28

Приведены современные данные литературы по обоснованию включения в комплексную терапию

стероидчувствительных дерматозов, осложненных вторичной инфекцией, комбинированных

глюкокортикостероидных препаратов. Особое внимание уделено доказательным исследованиям эфорективности

и безопасности комбинированной терапии инфицированных хронических дерматозов препаратом Акридерм ГК.

Ключевые слова: инфицированные стероидчувствительные дерматозы, топическая терапия, бетаметазона

дипропионат, гентамицин, клотримазол, Акридерм ГК.

\section{opical therapy of infected corticosteroid-sensitive dermatoses}

\section{I.E. Torshina}

Smolensk State Medical University of Ministry of Health of Russia Krupskaya str., 28, Smolensk, 214019, Russia

The article presents the current literature data on the rationale for the inclusion in complex therapy (combined corticosteroid drugs) for patients with steroid-sensitive dermatoses complicated by secondary infection.

This article contains information definitive studies of efficacy and safety of combination therapy of infected chronic dermatosis drug Akriderm GC

Key words: infected steroid-sensitive dermatoses, topical therapy, bematetazona dipropionate, gentamicin, clotrimazole, Akriderm GK.

Corresponding author: irina-torsina@ya.ru. Vestnik Dermatologii i Venerologii 2015; 5: 102_108. 
У пациентов-атопиков кожный покров более уязвим по отношению к инфрекциям.

A. Wollenberg, C. Zoch, S. Wetzel et al.

Значительную часть дерматологической патологии в практике врача-дерматовенеролога занимают так называемые стероидчувствительные дерматозы: аллергические и токсико-аллергические дерматиты, экзема, ограниченный нейродермит и др. $[1,2]$. Однако особое место из числа стероидчувствительных дерматозов принадлежит атопическому дерматиту, что обусловлено неуклонно возрастающим числом больных, особенностями хронического течения дерматоза, высоким риском развития осложнений, значительным снижением качества жизни пациентов [3, 4].

У больных стероидчувствительными дерматозами отмечается резкое снижение бактерицидных свойств кожи, которые у здорового человека обеспечиваются рядом взаимосвязанных фракторов [5-8]:

1) целостностью рогового слоя и фризиологической десквамацией;

2) особым химическим составом кожного сала и пота (гликофосфолипиды, свободные жирные кислоты), дающим бактериостатический эффрект, селективный для патогенной микробиоты;
3) кислой реакцией кератина и наличием водно-липидной мантии с высокой концентрацией водородных ионов в пределах $\mathrm{pH} 3,5-6,7$;

4) активностью и достаточным уровнем антимикробных пептидов.

В настоящее время именно роли антимикробных пептидов (АМП) в противостоянии сапрофитной и патогенной микробиоте придается большое значение. Генетически обусловленное снижение экспрессии бета-дефензина-2 в роговом слое эпидермиса у больных атопическим дерматитом приводит к снижению содержания АМП: кателицидинов и дефензинов $[9,10]$.

Известно, что АМП, являясь частью иммунной системы, в большом количестве содержатся в коже и имеют широкий спектр антимикробной активности, что позволяет называть их естественными антибиотиками кожи. Рядом исследований установлено, что в результате прямой антимикробной активности АМП способны уничтожать грамотрицательные, грамположительные бактерии, вирусные частицы и некоторые виды патогенных грибов $[9,10]$.

За счет воздействия на процессы хемотаксиса и ангиогенеза наряду с этиологическими фракторами АМП могут играть и патогенетическую роль в развитии ряда заболеваний, в частности атопического дерматита (рис. 1). Именно в коже у больных атопическим дерматитом при расчесывании не обнаруживается адекватного увеличения синтеза АМП, следствием чего является высокая чувствительность атопичной

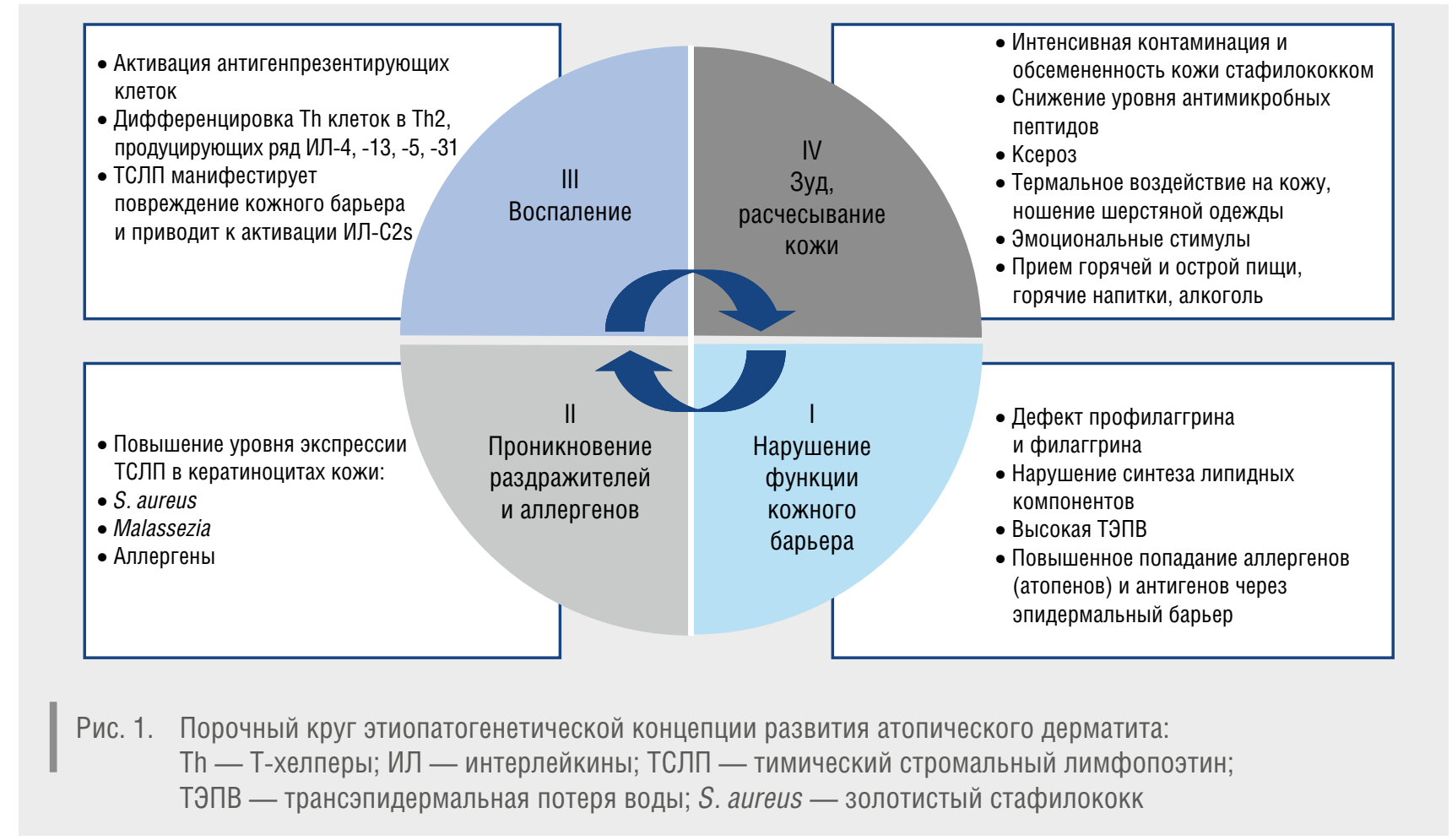


кожи к Staphylococcus aureus (в отличие от псориаза, где уровень АМП выше нормальных значений при расчесывании кожи) [9-11].

Выраженное снижение уровня и десицит АМП у больных атопическим дерматитом приводят к парадоксально высокой частоте обсеменения патогенной микробиотой:

1) в очагах воспаления $S$. aureus обнаруживается в 90\% случаев (в сравнении со здоровыми лицами, у которых частота обнаружения S. aureus не превышает 5\%);

2) увеличение риска развития грибковой и вирусной инвазии [11-14].

Взаимосвязи между клетками кожи больного атопией и стафилококком таковы, что клеточная стенка большинства штаммов $S$. aureus содержит рецепторы (адгезины) к ламелину и фибронектину эпидермиса и дермы. Фибриллярные и аморфные структуры между клетками стафилококка и корнеоцита формируют бактериальную биопленку на поверхности кожи, усиливающую адгезию стафилококка.

Дальнейшая активность $S$. aureus проявляется образованием энтеротоксинов (в 75\% случаев), которые представляют собой суперантигены, ингибирующие апоптоз клеток воспалительного инфильтрата и обусловливающие хронизацию процесса. Показано, что стафилококки продуцируют протеиназы, которые могут разрушать корнеодесмосомы. Кроме того, S. aureus секретирует сфингозиндеацилазу и глицерофоссролипиды, которые могут влиять на формирование липидных пластов в эпидермисе [12, 14].

Экзотоксины вызывают разрушение клеточных мембран, высвобождение входящих в ее состав фосфолипидов, арахидоновой и других полиненасыщенных жирных кислот, из которых при участии макрофагов и других клеток иммунной системы начинается бурный синтез простагландинов (простагландиновый каскад) и лейкотриенов, играющих важную роль в развертывании аллергических реакций, специфического воспаления, сопровождающегося разрушением клеточных и молекулярных связей с образованием свободных радикалов и гидропероксидов жирных кислот. Формирующийся порочный круг, называемый окислительным стрессом, приводит к повреждению клеток эпидермиса и развитию хронического воспаления в более глубоких слоях кожи $[14,15]$.

Учитывая тот фракт, что АМП принимают участие в регуляции выработки провоспалительных цитокинов и обладают способностью влияния на репаративные процессы в коже, недостаток АМП в коже больных с атопией неизбежно отражается на сохранении активности воспалительного процесса, его хронизации и отсутствии тенденции к восстановлению функциональных свойств кожи [9-12, 16].

Следовательно, тяжесть течения атопического дерматита характеризуется не только прямой корреляционной зависимостью со сниженным уровнем
АМП, но и высокой обсемененностью кожи патогенной микробиотой, среди которой главенствующую роль играет $S$. aureus.

С другой стороны, штаммы $S$. aureus и грибы рода Malassezia имеют лиганды Toll-подобных рецепторов, активация которых приводит к высвобождению продуцирующегося в коже тимического стромального лимфопоэтина (ТСЛП). Установлено, что ТСЛП активирует лимфоидные клетки врожденного иммунитета 2-го типа, что стимулирует синтез ими ряда провоспалительных интерлейкинов (ИЛ-4, -13, -5) и обеспечивает длительное сохранение воспаления в коже (см. рис. 1) [17].

Таким образом, микробиота кожи (S. aureus, грибы рода Malassezia) неизбежно утяжеляет течение основного заболевания посредством стимуляции выброса ТСлП клетками кератиноцитов. Негативное влияние патогенной микробиоты на течение хронического иммунозависимого воспалительного дерматоза диктует необходимость контроля над обсемененностью ключевых микробных агентов - $S$. aureus и грибов родов Malassezia и Candida (рис. 2) [18-22].

В случае атопического дерматита и ряда других стероидчувствительных дерматозов, осложненных вторичной инфекцией, показано применение антибактериальных средств: ингибиторозащищенных пенициллинов, цефралоспоринов 1-го или 2-го поколения, макролидов и/или фтторхинолонов. Однако при колонизации кожи метициллинрезистентными штаммами S. aureus выбор антибактериального средства может быть ограничен [23-25].

С целью контроля над микробиотой (в том числе и метициллинрезистентными штаммами S. aureus) как во взрослой, так и в педиатрической практике может быть использован гентамицин, который становится препаратом выбора в терапии не только осложненных форм атопического дерматита, но и у больных хроническими стероидчувствительными дерматозами в сочетании с сахарным диабетом и инфекцией Pseudomonas aeruginosa [26-28].

Индукция иммунного ответа по IgE-зависимому типу аллергических реакций обеспечивается присутствием грибов родов Malassezia и Candida в воспалительном очаге стероидчувствительного дерматоза, а также в случае различных вариантов развития дерматозов смешанной этиологии. Сенсибилизирующая активность у микотических аллергенов может быть даже более выраженной в сравнении с бактериальными. Присоединение грибковой инфекции способствует более торпидному течению атопического дерматита и снижает эффективность проводимой терапии [21]. Следовательно, применение комбинированных топических препаратов, содержащих клотримазол, является патогенетически обоснованным методом в терапии микробной экземы [19, 21].

Парадоксальным на первый взгляд является использование топических кортикостероидов (ТKC) 


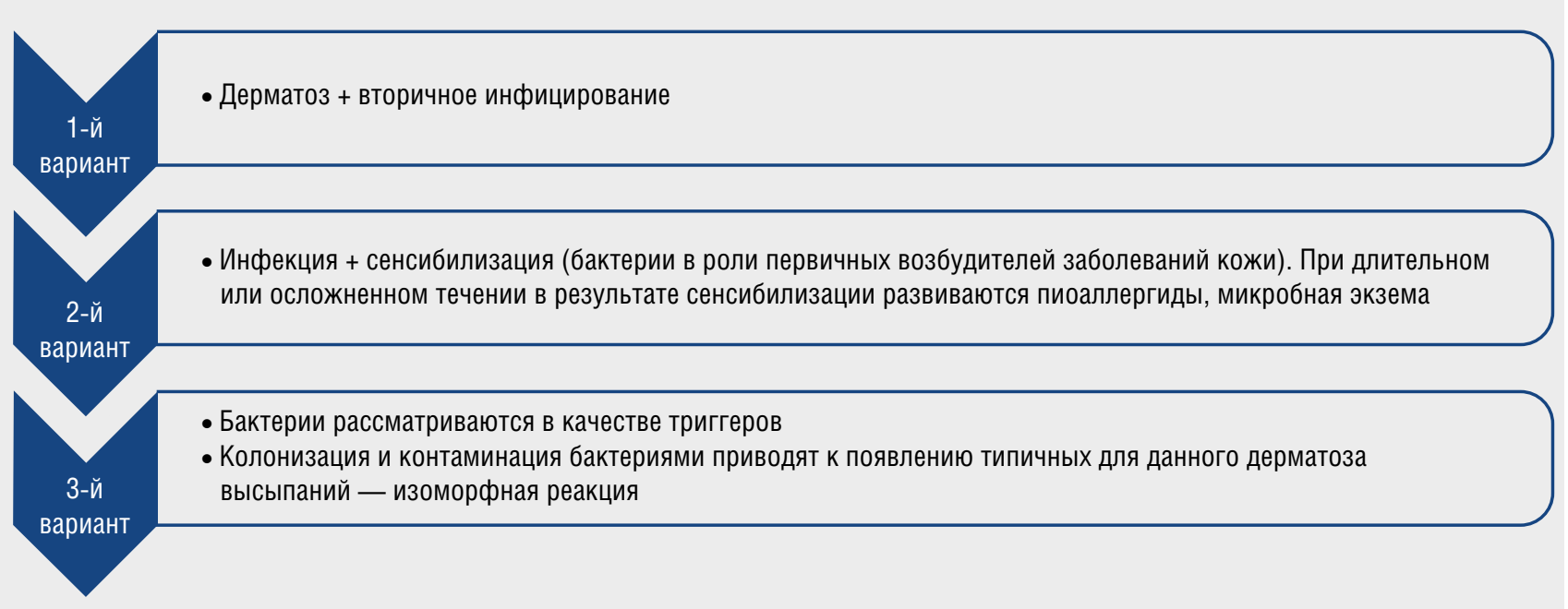

Рис. 2. Варианты развития и патогенеза дерматозов сочетанной этиологии

в тех клинических случаях, когда развивается вторичное бактериально-грибковое инфицирование иммунозависимого стероидчувствительного дерматоза. Однако ТKС способны подавлять экспрессию ТСлП в кератиноцитах, активированных в процессе воспалительной реакции. В результате терапии инфицированных вторичной микрофлорой стероидчувствительных дерматозов с использованием ТKС наблюдается:

1) снижение обсемененности кожи штаммами S. aureus и грибами рода Malassezia;

2) повышение резистентности к патогенам на фроне активации защиты от агрессии нормальной сапрофитной микробиоты кожи;

3) восстановление естественной бактерицидности кожи;

4) постепенная репарация кожи.

У больных атопическим дерматитом применение TKC в течение 7 дней приводит к уменьшению колонизации $S$. aureus, а продолжение использования до 14 дней - к элиминации S. aureus. Введение в TKC антибактериального компонента повышает эфрфективность терапии больных с осложненными фрормами стероидчувствительных дерматозов. На практике действие комбинированных ТKС проявляется значительным снижением времени разрешения клинической симптоматики и коррелирует с уменьшением титра бактерий [28-30].

Комбинированный состав топических средств позволяет воздействовать на основное заболевание и вторичную фрлору [30, 31]. К таким комбинированным препаратам, эффективным в терапии дерматозов, осложненных вторичной бактериальной и/или микотической инфекцией, относится препарат Акридерм ГК [31-33].
Препарат Акридерм ГК (мазь и крем) успешно используется в терапии атопического дерматита, других острых и хронических иммунозависимых дерматозов, осложненных бактериальной и/или микотической инфекцией. Оптимальная комбинированная фрормула препарата Акридерм ГК обеспечена сочетанием бетаметазона дипропионата 0,05\%, гентамицина сульфата $0,1 \%$ и клотримазола $1 \%$.

Немаловажное значение имеют не только активные компоненты препарата, но и его основа. Крем Акридерм ГК имеет гидрофильную эмульсионную основу, обладающую эмолиентным увлажняющим свойством, содержит нипагин (метиловый эфир параоксибензойной кислоты) с антимикробным и антисептическим эффректом. В составе основы препарата энхансер пропиленгликоль, потенцирующий действие глюкокортикостероидов и усиливающий антимикробный эффект нипагина.

Бетаметазона дипропионат, внедренный в клиническую практику в 70-80-е годы XX столетия, является b-изомером дексаметазона, имеет только один атом фртора, что значительно снижает риск побочных эффектов, но без снижения противовоспалительной активности. Бетаметазона дипропионат тормозит накопление лейкоцитов, высвобождение лизосомальных ферментов и провоспалительных медиаторов в очаге воспаления, угнетает фрагоцитоз, снижает сосудистотканевую проницаемость, препятствует развитию воспалительного отека.

Гентамицин - антибиотик широкого спектра действия из группы аминогликозидов. Он оказывает бактерицидное действие в отношении возбудителей первичных и вторичных бактериальных инфекций 
кожи. Антибактериальное действие гентамицина сульфата проявляется в отношении значительного спектра возбудителей: Staphylococcus spp., Pseudomonas spp., Proteus spp., Esherichia coli, Klebsiella spp., Enterococcus faecalis, Shigella spp. и др. Доказан бактерицидный эффрект антибиотика гентамицина в отношении всего спектра возбудителей микробной экземы [31-33].

Клотримазол - универсальное антимикотическое средство, поскольку обладает активностью в отношении дерматофитов, грибов рода Candida, возбудителей разноцветного лишая и эритразмы. Механизм действия клотримазола заключается в подавлении синтеза эргостерола - основной части клеточной стенки гриба, влиянии на митохондриальные пероксидазные фрерменты с последующим повышением концентрации перекиси водорода, лизисе грибковых клеток (фунгицидный эффект).

Выраженный клинический эффрект препарата Акридерм ГК обусловлен высокой лечебной активностью каждого его компонента, удачным сочетанием действующих начал в его составе, создающим эффект симбиоза, и доказан при ряде заболеваний.

Многочисленные отечественные исследования показали, что Акридерм ГК обладает высокой терапевтической эффрективностью при лечении дерматозов, осложненных бактериальной и микотической инфекцией. Препарат хорошо переносится пациентами, не имеет побочных эффектов и осложнений, удобен в применении, не пачкает одежду, не имеет запаха, способствует уменьшению и/или исчезновению зуда и чувства жжения, уменьшению явлений воспаления, экссудации и импетигенизации [31-33].

Эфрфективность и безопасность крема Акридерм ГК доказана в терапии детей с аллергическими дерматитами в возрасте больных от 1 года до 16 лет [33]. Применение препарата 2 раза в сутки в течение 7 дней привело к достоверному уменьшению площади поражения кожи и регрессу бактериально-аллергического воспаления.

В результате проведенных исследований отмечен положительный клинический эфффект у 95\% пациентов с развитием клинического излечения у $43 \%$ больных, значительного улучшения у $30 \%$, улучшения у $43 \%$. Сроки разрешения основных симптомов заболевания колебались от 5 до 7 дней с отличной переносимостью препарата у 98\% пациентов [31-33].

В медицинском центре «Академия здоровья» ГБОУ ВПО «Смоленский государственный медицинский университет» Минздрава России за 2007-2014 гг. в составе комплексной терапии нами успешно применялись мазь и крем Акридерм ГК у 218 больных в возрасте от 7 до 68 лет с различными стероидчувствительными дерматозами, осложненными вторичной инфекцией: атопическим дерматитом (74 пациента), микробной экземой (60 больных), аллергическим дерматитом (34 пациента), контактным дерматитом (28 больных), инсектным дерматитом (22 пациента).

Выбор лекарственной формы препарата (крем или мазь) определялся активностью и характером воспалительного процесса. В случаях острого экссудативного воспаления наружную терапию начинали с применения крема Акридерм ГК 1 раз в день тонким слоем на очаги поражения в течение 3-4 дней. В дальнейшем продолжали наружную противовоспалительную терапию со сменой лекарственной формы препарата на мазь Акридерм ГК также 1 раз в сутки в течение последующих 5-6 дней. В случаях хронического воспалительного пролиферативного процесса изначально назначался Акридерм ГК в форме мази. Ежедневная оценка клинических результатов показала, что на 3-4-й день от начала терапии в случаях острого воспаления отмечалось уменьшение зуда, регресс явлений гиперемии, отечности, экссудации с разрешением признаков воспаления. Эффрективность мази Акридерм ГК в случаях хронического воспаления проявлялась на 4-6-е сутки от начала терапии.

В результате последовательной смены различных лекарственных форм препарата Акридерм ГК в составе комплексной терапии отмечалось разрешение активности воспалительного процесса и явлений, связанных с развитием вторичной бактериальной и микотической фрлоры. Нами не отмечено ни одного случая побочных явлений. Таким образом, учитывая роль вторичной микробной и грибковой флоры в патогенезе хронических стероидчувствительных дерматозов, помимо традиционной наружной терапии необходимо назначение антибиотиков и антимикотиков, при этом предпочтение следует отдавать комбинированным препаратам. Назначение комбинированных препаратов, содержащих ТКС и антибиотики, при бактериальном поражении часто провоцирует рост сапрофитной кандидозной фрлоры и грибов рода Malassezia и осложняет течение основного заболевания. Поэтому наиболее эффективными в качестве местной терапии являются комбинированные препараты, в состав которых кроме топических глюкокортикостероидов входят антибактериальные и антимикотические компоненты, что позволяет воздействовать одновременно на все звенья патологического процесса хронически протекающих стероидчувствительных иммунозависимых дерматозов.

Полученные нами данные по результатам практического применения различных форм комбинированного препарата Акридерм ГК вполне согласуются с многочисленными исследованиями, которые показали его высокую терапевтическую эффрективность при лечении стероидчувствительных дерматозов, осложненных вторичной инфекцией, выраженную в снижении длительности проводимой терапии и числа обострений, увеличении сроков ремиссии при отсутствии значимых побочных явлений. 


\section{Литература}

1. Resursy i deyatel'nost' meditsinskikh organizatsii dermato-venerologicheskogo profilya. Zabolevaemost' infektsiyami, peredavaemymi polovym putem, zaraznymi kozhnymi boleznyami i boleznyami kozhi. Statisticheskie materialy. Sbornik, Moskva, 2013. [Ресурсы и деятельность медицинских организаций дерматовенерологического профииля. Заболеваемость инфекциями, передаваемыми половым путем, заразными кожными болезнями и болезнями кожи. Статистические материалы. Сборник. М, 2013.]

2. Kasikhina E.I., Glazko I.I., Ryabchikova M.D. Mikst-infektsiya v praktike dermatologa: osobennosti patogeneza i puti resheniya Klini dermatol venerol 2014; 4: 56-60. [Касихина Е.И., Глазко И.И., Рябчикова М.Д. Микстинсфекция в практике дерматолога: особенности патогенеза и пути решения Клин дерматол венерол 2014; 4: 56-60.]

3. Potekaev N.N., Sherina T.F. K voprosu ob assotsiatsii dermatozov i mikozov kozhi. Ros zhurn kozhn i ven bol 2004; 6: 55-57. [Потекаев Н.Н., Шерина Т.Ф. К вопросу об ассоциации дерматозов и микозов кожи. Рос журн кожн вен бол 2004; 6: 55-57.]

4. Kotrekhova L.P. Diagnostika i ratsional'naya terapiya dermatozov sochetannoi etiologii. Consilium medicum (prilozhenie "Dermatologiya") 2010; 4: 6-11. [Котрехова Л.П. Диагностика и рациональная терапия дерматозов сочетанной этиологии. Consilium medicum (приложение «Дерматология») 2010; 4: 6-11.]

5. Wollenberg A., Zoch C., Wetzel S., Plewig G., Przybilla B. Predisposing factors and clinical features of eczema herpeticum - a retrospective analysis of 100 cases. J Am Acad Dermatol 2003; 49: 198-205. View Article Pub Med. doi: 3.3543718 .

6. Takai T., Ikeda S. Barrier dysfunction caused by environmental proteases in the pathogenesis of allergic diseases. Allergol Int 2011; 60: 25-35. doi: 4.0170813.

7. Zhang L.J., Guerrero-Juarez C.F., Hata T., Bapat S.P., Ramos R., Plikus M.V., Gallo R.L. Innate immunity. Dermal adipocytes protect against invasive Staphylococcus aureus skin infection. Science. 2015 Jan 2; 347 (6217): 67-71. doi: 4.2068963.

8. Nakatsuji T., Chiang H.I., Jiang S.B., Nagarajan H., Zengler K., Gallo R.L. The microbiome extends to subepidermal compartments of normal skin. Nature Commun. 2013 Feb 5; 4: 1431 doi: 3.898077

9. Jürgen Schauber, Richard L. Gallo. Antimicrobial peptides and the skin immune defense system J allergy clini immunol 2008; 122: 2: 261-266. doi: 4.0276732 .
10. Muehleisen B., Bikle D.D., Aguilera C., Burton D.W., Sen G.L., Deftos L.J., Gallo R.L. PTH/PTHrP and Vitamin D Control Antimicrobial Peptide Expression and Susceptibility to Bacterial Skin Infection. Science Transl Med 2012 May; 23: 4 (135): 135_66. doi: 3.6371732

11. Salah L.A., Faergemann J. A Retrospective Analysis of Skin Bacterial Colonisation, Susceptibility and Resistance in Atopic Dermatitis and Impetigo Patients. Acta Derm Venereol 2014 Nov; 4. doi: 10.2340/00015555-1996.

12. Jinnestål C.L., Belfrage E., Bäck O., Schmidtchen A., Sonesson A. Skin barrier impairment correlates with cutaneous Staphylococcus aureus colonization and sensitization to skinassociated microbial antigens in adult patients with atopic dermatitis. Int J Dermatol 2014; 53(1):27-33. doi: 5.6857157.

13. Zhan Gao, Guillermo I. Perez-Perez, Yu Chen, Martin J. Blaser. Quantitation of Major Human Cutaneous Bacterial and Fungal Populations. J Clin Microbial Oct 2010; 48 (10): 35753581. doi: 3.1251745 .

14. Miedzobrodzki J., Kaszycki P., Bialecka A. et al. Proteolytic activity of Staphylococcus aureus strains isolated from the colonized skin of patients with acute phase atopic dermatitis. Eur $\mathrm{J}$ Clin Microbiol Infect Dis 2002; 21: 269_76. doi: 4.7429633 .

15. Leung D.Y. New insights into atopic dermatitis: role of skin barrier and immune dysregulation. Allergol Int. 2013; 62 (2): 151—61. doi: 3.1840272 .

16. Ertneeva I.Ya., Matushevskaya E.V., Svirshchevskaya E.V. i soavt. Kliniko-immunologicheskie pokazateli u bol'nykh atopicheskim dermatitom pri lechenii preparatami linii akriderm. Klin dermatol i venerol 2008; 5: 35-39. [Эртнеева И.Я., Матушевская Е.В., Свирщевская Е.В. и соавт. Клинико-иммунологические показатели у больных атопическим дерматитом при лечении препаратами линии акридерм. Клин дерматол венерол 2008; 5: 35-39.]

17. Lai Y.P., Di Nardo A., Nakatsuji T., Leichtle A., Yang Y., Cogen A.L., Wu Zi-Rong, Hooper L.V., Schmidt R.R., von Aulock S., Radek K.A., Huang C., Ryan A.F., Gallo R.L. Commensal bacteria regulate Toll-like receptor 3-dependent inflammation after skin injury. Nature Medicine 2009, Dec; 15 (12): 1377—82. doi: 4.36221

18. Rajka G., Barlinn C. On the significance of the trichophytin reactivity in atopic dermatitis. Acta Derm Venereol 1979; 59: 45—47.
19. Voronina V.R., Smolkin Yu.S., Cheburkin A.A. Rol' gribkovoi i bakterial'noi flory kozhi v patogeneze atopicheskogo dermatita. Vestn dermatol venerol 2003; 1: 16-19. [Воронина В.P., Смолкин Ю.С., Чебуркин А.А. Роль грибковой и бактериальной фрлоры кожи в патогенезе атопического дерматита. Вестн дерматол венерол 2003; (1): 16-19.]

20. Jagielski T., Rup E., Ziółkowska A., Roeske K. Macura A.B., Bielecki J. Distribution of Malassezia species on the skin of patients with atopic dermatitis, psoriasis, and healthy volunteers assessed by conventional and molecular identification methods. BMC Dermatol 2014; 14:3. doi: 5.5457253 .

21. Brodská P., Panzner P., Pizinger K., SchmidGrendelmeier P. IgE-mediated sensitization to malassezia in atopic dermatitis: more common in male patients and in head and neck type. Dermatitis 2014; 25 (3): 120—6. doi: 7.2890797.

22. Gerasimchuk E.V. Krem Akriderm-GK, kak sredstvo dlya lecheniya smeshannykh infektsii kozhi. Klin dermatol venerol 2005; 4: 142146. [Герасимчук Е.В. Крем Акридерм-ГК как средство для лечения смешанных инфекций кожи. Клин дерматол венерол 2005; 4: $142-146$.

23. Cohen P.R. Community-acquired methicillinresistant Staphylococcus aureus: skin infection presenting as an axillary abscess with cellulitis in a college athlete. Skin med. 2005, Mar-Apr; 4 (2): 115-8. doi: 4.7210684.

24. Paintsil E. Pediatric community-acquired methicillin-resistant Staphylococcus aureus infection and colonization: trends and management. Curr Opin Pediatr. 2007, Feb; 19 (1): 75—82. doi: 4.155836

25. Lipsky B.A., Kuss M., Edmonds M., Reyzelman A., Sigal F. Topical application of a gentamicin-collagen sponge combined with systemic antibiotic therapy for the treatment of diabetic foot infections of moderate severity: a randomized, controlled, multicenter clinical trial. Am Pediatr Med Assoc. 2012 May-Jun; 102 (3): 223-32. doi: 3.9620874.

26. Ring et al. Guidelines for treatment of atopic eczema (atopic dermatitis) JEADV 2012; 26: 1045-1060. doi: 2.3502793.

27. Diana Rubel et al. Consensus guidelines for management of atopic dermatitis: An AsiaPacific perspective. J of dermatology. 2013; 40: 160_171 doi: 3.6350408.

28. Belousova T.A., Goryachkina M.V. Algoritm naruzhnoi terapii dermatozov sochetannoi etiologii. Farmakoterapiya v dermatovenerologii 2011; 5 : 146-152. [Белоусова Т.А., Горячкина М.В. Алгоритм наружной терапии дерматозов сочетанной этиологии. Фармакотерапия в дерматовенерологии 2011; 5: 146-152.] 
29. Svirshchevskaya E.V., Matushevskaya E.V. Topicheskie glyukokortikosteroidy i blokatory kal'tsenevrina v dermatologii, Sovrem probl dermatovenerol, immunol vrach kosmetol 2012; 1: 57-62. [Свирщевская Е.В., Матушевская Е.В. Топические глюкокортикостероиды и блокаторы кальценеврина в дерматологии. Соврем пробл дерматовенерол, иммунол и врач косметол 2012; 1: 57-62.]

30. Gong J.Q., Lin L., Lin T. et al. Skin colonization by Staphylococcus aureus in patients with eczema and atopic dermatitis and relevant combined topical therapy: a double-blind multicentre randomized controlled trial. Br J Dermatol 2006; 155 (4): 680-7. doi: 4.1864605 .
31. Matushevskaya E.V., Shakurov I.G., Khismatullina Z.R. Effektivnost' i perenosimost' linii Akriderm $\mathrm{v}$ praktike dermatovenerologa. Klin dermatol venerol 2008; 2: 45—48. [Матушевская Е.В., Шакуров И.Г., Хисматуллина 3.Р. Эфффективность и переносимость линии Акридерм в практике дерматовенеролога. Клин дерматол венерол 2008; 2: 45-48.]

32. N.N. Filimonkova, E.A. Bahlykova Combined topical therapy of chronic dermatoses. Vestn dermatol venerol 2015; 3: 147-152. [Филимонкова Н.Н., Бахлыкова Е.А. Комбинированная топическая терапия хронических дерматозов. Вестн дерматол венерологии 2015; 3: 147-152.]
33. Lyan N.A., Kornacheva L.A., Cheburkin A.A. Effektivnost' i bezopasnost' primeneniya krema "Akriderm GK" u detei s allergicheskimi dermatitami. Allergol i immunol v pediatrii 2006; 1 (8): 15-19. [Лян Н.А., Корначева Л.А., Чебуркин А.А. Эфффективность и безопасность применения крема «Акридерм ГК» у детей с аллергическими дерматитами. Аллергол и иммунол в педиатрии 2006; 1 (8): 15-19.]

об авторе:

И.Е. Торшина - д.м.н., доцент зав. кафредрой кожных и венерических болезней с курсом медицинской косметологии ГБОУ ВПО СГМУ Минздрава России, Смоленск

\section{Конфликт интересов}

Авторы заявляют об отсутствии потенциального конфлликта интересов, требующего раскрытия в данной статье 